\title{
Evaluation of Enhanced Low Dose Rate Sensitivity in Discrete Bipolar Junction Transistors
}

\author{
Dakai Chen, Member, IEEE, Alyson Topper, James Forney, Brian Triggs, Tony Kazmakites, \\ Ronald Pease, Fellow, IEEE, Raymond Ladbury, Member, IEEE, and Kenneth LaBel, \\ Member, IEEE
}

\begin{abstract}
We evaluate the low dose rate sensitivity in several families of discrete bipolar transistors across device parameter, quality assurance level, and irradiation bias configuration. The 2N2222 showed the most significant low dose rate sensitivity, with low dose rate enhancement factor of $\times 3.91$ after 100 krad(Si). The 2N2907 also showed critical degradation levels. The devices irradiated at $10 \mathrm{mrad}(\mathrm{Si}) / \mathrm{s}$ exceeded specifications after 40 and 50 krad(Si) for the 2 N2222 and 2 N2907 devices, respectively.
\end{abstract}

\section{InTRODUCTION}

$\mathrm{E}$ nhanced-low-dose-rate-sensitivity (ELDRS) has remained a challenge for radiation hardness assurance of linear bipolar integrated circuits (IC). Although ELDRS originates in discrete bipolar junction transistors (BJT), its magnitude is often enhanced in linear ICs [1]. Therefore, while there are qualification standards for linear bipolar circuits (MIL-STD883H, TEST METHOD 1019.8), there is currently no standard test requirement to screen ELDRS in discrete bipolar transistors [2]. No study up to date has systematically evaluated the low dose rate response of a wide range of discrete devices with varying power level, switching speed, breakdown voltage, and polarity.

Previous studies by Johnston et al. found minimal dose rate dependence for discrete BJTs [1]. In contrast, Nowlin et al. observed approximately $\times 2$ in the low dose rate enhancement factor of the transistor current gain for highly scaled transistors [3]. The low dose rate enhancement factor (LDR $\mathrm{EF}$ ) is a Fig. of merit commonly used to measure the magnitude of ELDRS. It is defined as the ratio of the radiation-induced shift in a sensitive device parameter at low

Manuscript received XX, 2012. This work was supported in part by the NASA Electronic Parts and Packaging Program (NEPP) and Defense Threat Reduction Agency (DTRA) under IACRO\# 11-4977I.

Dakai Chen, Raymond Ladbury, and Kenneth LaBel are with NASA Goddard Space Flight Center, code 561.4, Greenbelt, MD 20771 USA (telephone: 301-286-8595, e-mail: dakai.chen-1@nasa.gov).

Alyson Topper and James Forney are with MEI Technologies Inc. in support of NASA Goddard Space Flight Center, Greenbelt, MD 20771 USA (telephone: 301-286-2014, e-mail: alyson.d.topper@nasa.gov).

Brian Triggs and Tony Kazmakites are with SEMICOA Corp. 333 McCormick Ave, Costa Mesa, CA 92626 USA (telephone: 714-242-3029, email: btriggs@semicoa.com).

Ronald Pease is with RLP Research 8 Songbird Lane, Los Lunas, NM 87031 USA (telephone: 505-565-0548, e-mail: rlpease@hughes.net) dose rate to that at high dose rate [2]. The highly scaled devices that showed ELDRS have processes that are similar to the processes in linear ICs, rather than in conventional discrete devices. In particular, the highly scaled devices have much higher emitter perimeter to area ratios than that typically found in discrete devices. The difference in device dimensions likely contributed to the difference in the radiation response. The technology processes and designs of discrete devices have evolved since the early investigations. The changes in various device parameters can significantly impact the low dose rate sensitivity, a phenomenon which we still do not completely understand, despite several investigations on the physical mechanism of ELDRS [4]-[6].

A recent study of a large array of linear circuits from various manufacturers revealed that the magnitude of ELDRS can continue to increase at dose rates as low as 0.5 $\operatorname{mrad}(\mathrm{Si}) / \mathrm{s}$, which is a factor of $\times 20$ less than the standard test dose rate [7]. The low dose rate enhancement also varies significantly with different device types, such that worst cases show functional failures at $15 \mathrm{krad}(\mathrm{Si})$. In addition, results presented at the 2011 JEDEC G-12 meeting showed that the gain degradation for 2N2907 devices irradiated at 100 $\mathrm{mrad}(\mathrm{Si}) / \mathrm{s}$ exceeded the manufacturer's specifications at 100 $\operatorname{krad}(\mathrm{Si})[8]$.

These findings indicate that the impact of ELDRS may be more significant than previously understood. Since discrete bipolar transistors are used prevalently in space flight systems, it is necessary to assess the ELDRS susceptibility of a large sample size of discrete bipolar devices with varying device parameters.

\section{Experimental}

We performed total dose testing on eight different part types from SEMICOA. The devices encompass a wide range of power, switching speed, breakdown voltage, and quality assurance levels. Table I shows the different part types, with the respective parametric specification, package type, and lot date code information. $\mathrm{V}_{\mathrm{CE}}$ and Min $\mathrm{I}_{\mathrm{C}}$ represent the collector-emitter breakdown voltage and minimum operating collector current, respectively. The devices here include JANS and JANSR quality assurance levels. The JANSR devices are radiation qualified up to $100 \mathrm{krad}(\mathrm{Si})$ at high dose 
TABLE I

Device information and results summary

\begin{tabular}{|c|c|c|c|c|c|c|c|c|c|}
\hline $\begin{array}{c}\text { Part } \\
\text { Number }\end{array}$ & Quality & $\begin{array}{l}\text { Package } \\
\text { Type }\end{array}$ & $\begin{array}{l}\text { Lot Date } \\
\text { Code }\end{array}$ & Polarity & $\begin{array}{l}V_{C E} \\
\text { (V) }\end{array}$ & $\begin{array}{l}\operatorname{Min}_{\mathrm{C}} \\
(\mathrm{A})\end{array}$ & $\begin{array}{l}\text { Power } \\
\text { (W) }\end{array}$ & $\begin{array}{l}\text { Freq } \\
(\mathrm{MHz})\end{array}$ & Results Summary \\
\hline \multirow[b]{2}{*}{$2 \mathrm{~N} 2222 \mathrm{~A}$} & \multirow[b]{2}{*}{ JANSR } & TO-18 & \multirow[b]{2}{*}{ J1364 } & \multirow[b]{2}{*}{ NPN } & \multirow[b]{2}{*}{50} & \multirow[b]{2}{*}{0.8} & \multirow[b]{2}{*}{0.5} & \multirow[b]{2}{*}{250} & \multirow{2}{*}{$\begin{array}{l}35<\mathrm{h}_{\mathrm{FE}}<40 \mathrm{krad}(\mathrm{Si}) \\
\mathrm{LDR} \text { EF }=3.91100 \mathrm{krad}(\mathrm{Si}\end{array}$} \\
\hline & & UB & & & & & & & \\
\hline \multirow[b]{2}{*}{$2 \mathrm{~N} 2907 \mathrm{~A}$} & \multirow[b]{2}{*}{ JANSR } & TO-18 & \multirow[b]{2}{*}{ J1324 } & \multirow[b]{2}{*}{ PNP } & \multirow[b]{2}{*}{60} & \multirow[b]{2}{*}{0.6} & \multirow[b]{2}{*}{0.5} & \multirow[b]{2}{*}{200} & \multirow{2}{*}{$\begin{array}{l}40<h_{F E}<50 \mathrm{krad}(\mathrm{Si}) \\
\operatorname{LDR} E F=1.78100 \mathrm{krad}(\mathrm{Si})\end{array}$} \\
\hline & & UBC & & & & & & & \\
\hline 2N2369A & JAN & TO-18 & J1934 & NPN & 15 & 0.1 & 0.36 & 500 & $\begin{array}{l}>100 \mathrm{krad}(\mathrm{Si}) \\
\mathrm{LDR} \mathrm{EF}<1.5\end{array}$ \\
\hline 2N3700 & JANSR & TO-18 & J1818 & NPN & 80 & 1 & 0.5 & 100 & $\begin{array}{l}>100 \mathrm{krad}(\mathrm{Si}) \\
\mathrm{LDR} \mathrm{EF}<1.5\end{array}$ \\
\hline 2N5154 & JAN & TO-39 & J1727 & NPN & 80 & 2 & 1 & 70 & $\begin{array}{l}>100 \mathrm{krad}(\mathrm{Si}) \\
\operatorname{LDR} \mathrm{EF}=4.21100 \mathrm{krad}(\mathrm{Si})\end{array}$ \\
\hline 2N5153 & JAN & TO-39 & J1470 & PNP & 80 & 2 & 1 & 70 & $\begin{array}{l}>100 \mathrm{krad}(\mathrm{Si}) \\
\operatorname{LDR} \mathrm{EF}=1.85100 \mathrm{krad}(\mathrm{Si})\end{array}$ \\
\hline 2N2857 & JANSR & TO-72 & J1523 & NPN & 15 & 0.04 & 0.2 & 1000 & $\begin{array}{l}>20 \operatorname{krad}(\mathrm{Si}) \\
\mathrm{LDR} \mathrm{EF}<1.5\end{array}$ \\
\hline
\end{tabular}

rate. In cases such as the 2 N2222 and 2N2907, we also evaluated different package types with the same lot date codes.

The devices were placed inside aluminum and lead shielding boxes and irradiated with $1 \mathrm{MeV}^{60} \mathrm{Co}$ gamma rays at ambient temperature. The low dose rate and high dose rate irradiations were performed at a dose rate of 0.01 and 50 $\operatorname{rad}(\mathrm{Si}) / \mathrm{s}$, respectively. Four to five samples of each part type were irradiated under biased configuration (collector-emitter reverse biased to $80 \%$ of maximum rating with base open) and with terminals grounded, for each dose rate. One to two samples of each part type were used as controls. The devices were characterized using a Keithley $24351 \mathrm{~kW}$ pulse meter and a Keithley 100W source meter.

\section{Results}

Fig. 1 shows the normalized current gain as a function of the collector current, for devices irradiated at $10 \mathrm{mrad}(\mathrm{Si}) / \mathrm{s}$ to $50 \mathrm{krad}(\mathrm{Si})$. The normalized current gain here is defined as the ratio of the post-irradiation to pre-irradiation current gain. We note that the error bars in the Fig.s represent part-to-part standard deviation. The current gain degradation increases with decreasing $\mathrm{I}_{\mathrm{C}}$, as is commonly observed in bipolar transistors [9]. The radiation-induced increase in the recombination base current is proportionally more significant relative to the collector current, at the lower injection regions. Therefore the effect is more severe for lower $\mathrm{I}_{\mathrm{C}}$. The current gain degradation is particularly significant for the $2 \mathrm{~N} 2222$ and 2N2907 at the lower injection regions.

Various factors can influence the total dose response of discrete bipolar transistors. A previous study by Johnston et al. explored the effects of different device parameters on the radiation-induced degradation of discrete BJTs and bipolar linear ICs [1]. For example, the current gain degradation in some devices varied with the collector-emitter breakdown voltage [1]. The devices here did not show similar dependence in the breakdown voltage. Fig. 2 shows the radiation-induced change in the inverse current gain $\left(\Delta \mathrm{h}_{\mathrm{FE}}{ }^{-1}\right)$ as a function of the minimum device operating current, for devices irradiated to $50 \mathrm{krad}(\mathrm{Si})$ at low dose rate. We observed that the current gain degradation varied inversely with the minimum operating $\mathrm{I}_{\mathrm{C}}$. The $\Delta \mathrm{h}_{\mathrm{FE}}{ }^{-1}$ values for devices with the lowest operating currents were approximately one order of magnitude higher than for devices with the highest operating currents. However the low dose rate enhancement does not necessarily correlate with the minimum device operating range, as we show in Fig. 3.

Fig. 3 shows the low dose rate enhancement factor as a function of total dose for various device types. The LDR EF is calculated from the ratio of $\Delta \mathrm{h}_{\mathrm{FE}}{ }^{-1}$ at low dose rate to that at high dose rate. The error bars represent the percent error, given below

$$
\% \text { ERROR }=\sqrt{\left[\frac{1}{N}\left(\frac{\sigma}{\mu}\right)^{2}\right]_{\text {High }}+\left[\frac{1}{N}\left(\frac{\sigma}{\mu}\right)^{2}\right]_{\text {Low }}}
$$

where $\mathrm{N}$ is the samples size, $\sigma$ and $\mu$ are respectively the standard deviation and mean of the LDR EF factor at high and low dose rate.

The 2N2222 and 2N5154 showed the most significant low dose rate enhancement. However the degradation level in the 2N5154 is insignificant. The degradation in the 2N2907 was significant, even though the LDR EF was less than 2. In fact, the current gains exceeded the pre-irradiation specifications 


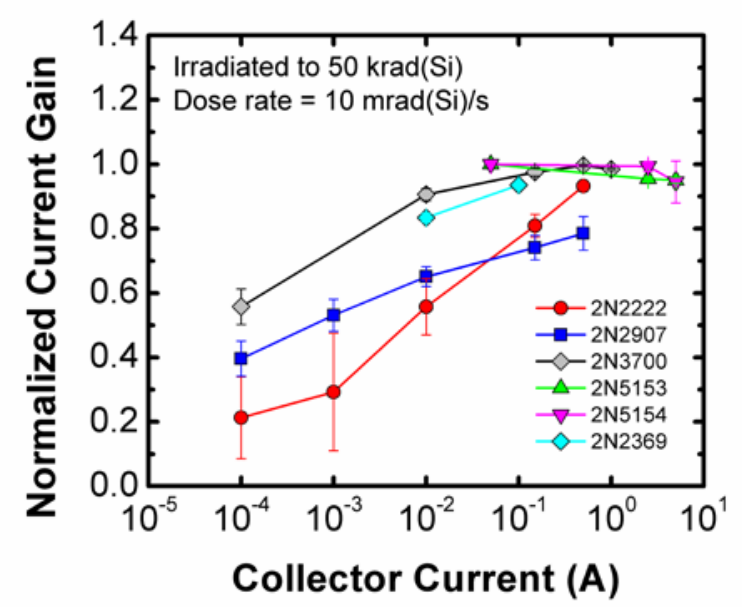

Fig. 1. Normalized current gain $\left(\mathrm{h}_{\mathrm{FE}-\mathrm{postrad}} / \mathrm{h}_{\mathrm{FE}-\mathrm{prrerad}}\right)$ as a function of collector current for various part types, irradiated to $50 \mathrm{krad}(\mathrm{Si})$ at 10 $\operatorname{mrad}(\mathrm{Si}) / \mathrm{s}$.

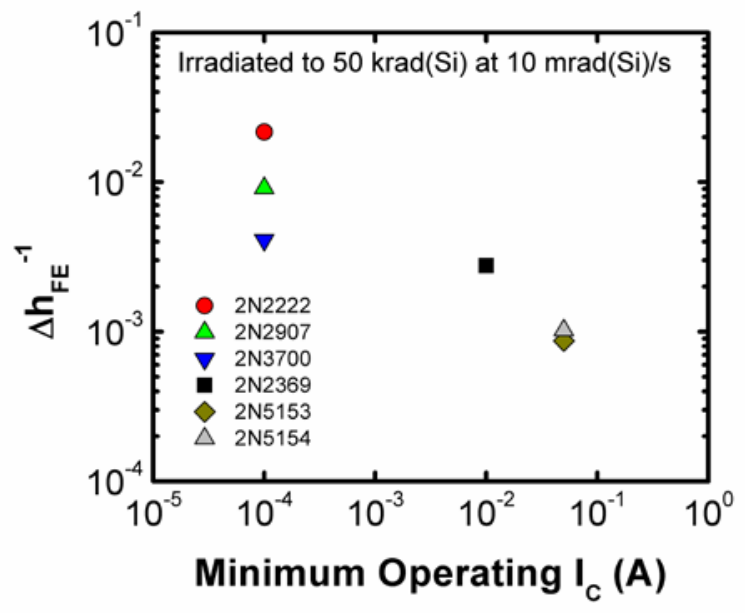

Fig. 2. Change in the inverse current gain as a function of the minimum device operating collector current, for various part types, irradiated to $50 \mathrm{krad}(\mathrm{Si})$ at $10 \mathrm{mrad}(\mathrm{Si}) / \mathrm{s}$

for the 2N2222 and 2N2907 devices irradiated at 10 $\operatorname{mrad}(\mathrm{Si}) / \mathrm{s}$, after 40 and $50 \mathrm{krad}(\mathrm{Si})$, respectively. And while the $2 \mathrm{~N} 3700$ has a minimum operating $\mathrm{I}_{\mathrm{C}}$ on the same order as the 2N2222, the parts exhibited no low dose rate enhancement.

The results show that the minimal device operating range directly impacts the magnitude of the radiation-induced degradation. However other process related parameters, beyond the electrical specifications, has significant impact to the level of low dose rate enhancement. We show and discuss the test results for each device type.

\section{N2222A}

The $2 \mathrm{~N} 2222 \mathrm{~A}$ is a general purpose, low power NPN transistor. We investigate devices with JANSR quality in TO18 metal can and UB (ceramic lid version) package types. All devices have identical wafer and lot date code.

The high dose rate data presented here are obtained from the UB packaged devices. The low dose rate data represent results for the TO-18 packaged devices. The low dose rate

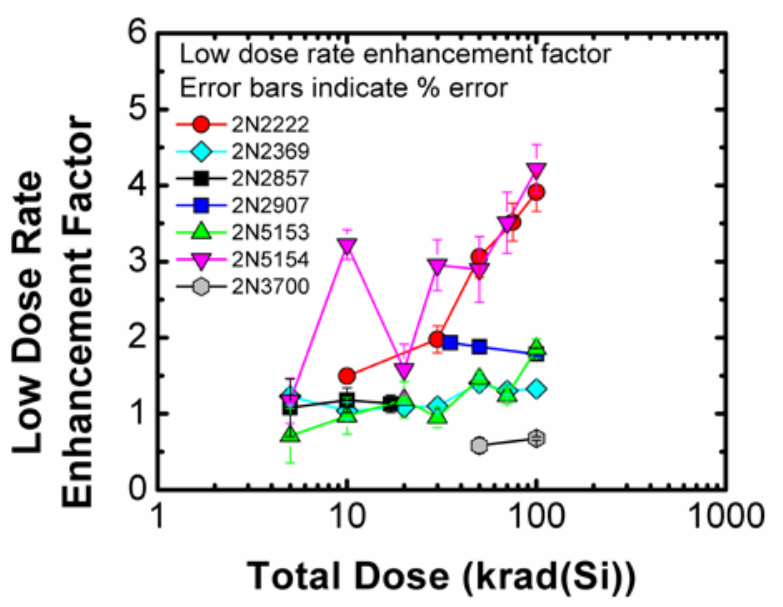

Fig. 3. The low dose rate enhancement factor as a function of dose (error bars represent \% error).

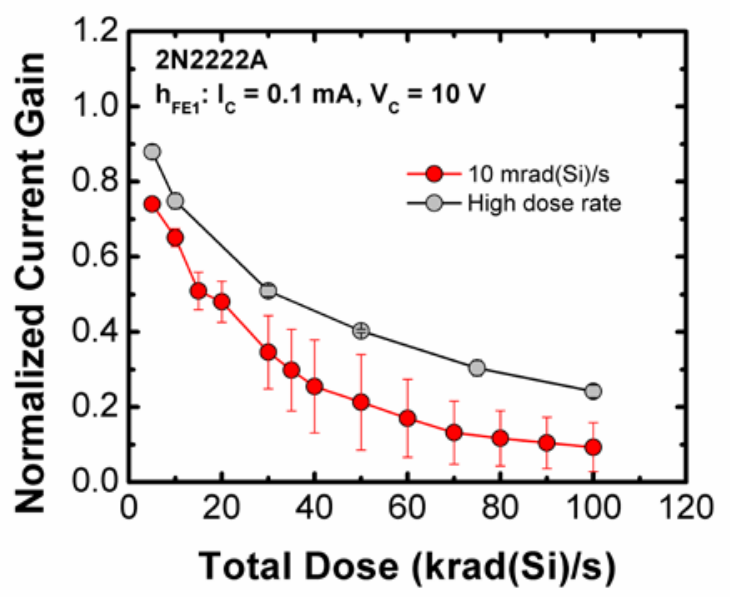

Fig. 4. Normalized current gain as a function of dose for the 2N2222, irradiated under bias at a high dose rate and $10 \operatorname{mrad}(\mathrm{Si}) / \mathrm{s}$.

testing for the UB packaged devices are in progress; their degradation response is similar to the TO-18 packaged devices up to $40 \mathrm{krad}(\mathrm{Si})$, within part-to-part standard deviation. In addition, the high dose rate results from the UB packaged devices are quantitatively identical to previous data from TO-18 packaged devices. The results indicate that it is viable to use the high dose rate data set from the UB packaged devices to examine the low dose rate sensitivity.

Fig. 4 shows the normalized current gain as a function of total dose for devices irradiated under bias at high dose rate and $10 \mathrm{mrad}(\mathrm{Si}) / \mathrm{s}$. We observed enhanced degradation to the current gain for devices irradiated at $10 \mathrm{mrad}(\mathrm{Si}) / \mathrm{s}$, relative to the devices irradiated at high dose rate. Fig. 5 shows the LDR $\mathrm{EF}$ as a function of dose. The LDR EF is approximately $\times 3.91$ after $100 \mathrm{krad}(\mathrm{Si})$.

In fact, two samples irradiated at $10 \mathrm{mrad}(\mathrm{Si}) / \mathrm{s}$ failed parametrically after $40 \mathrm{krad}(\mathrm{Si})$. Fig. 6 shows the current gain as a function of the operating $\mathrm{I}_{\mathrm{C}}$ after $50 \mathrm{krad}(\mathrm{Si})$. We see that the current gain of the devices irradiated at low dose rate 


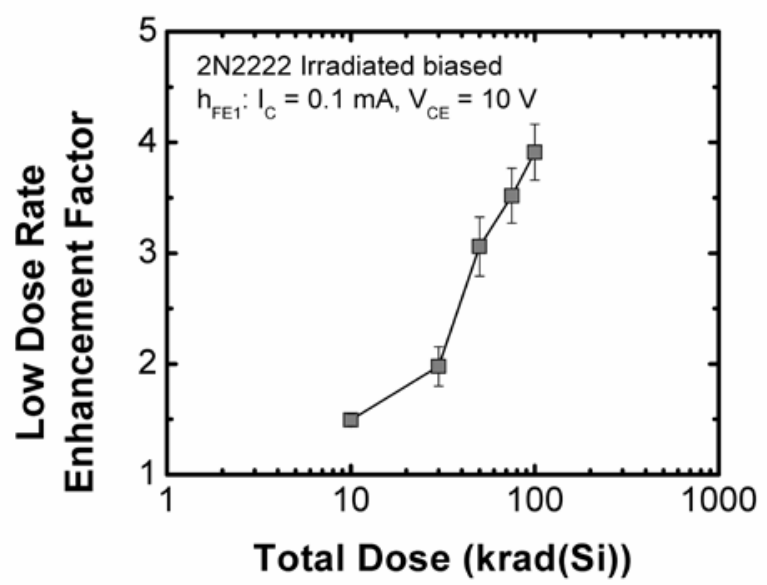

Fig. 5. The low dose rate enhancement factor as a function of dose for the 2N2222 irradiated under bias.

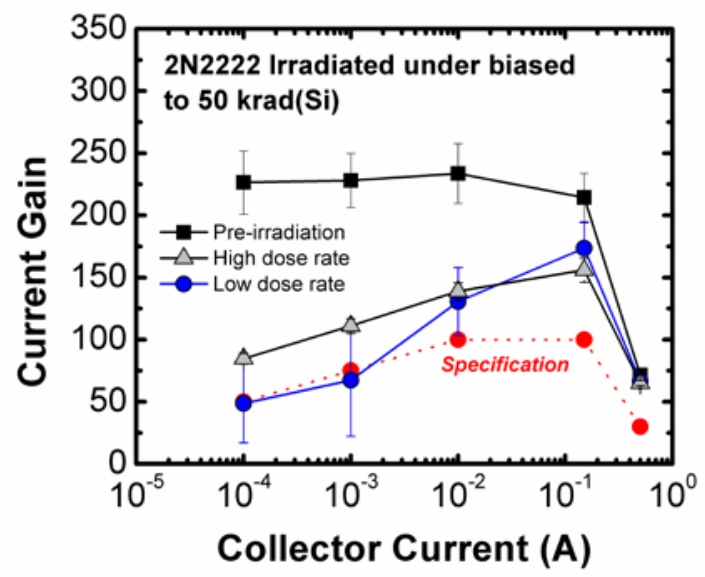

Fig. 6. Current gain as a function of the operating $\mathrm{I}_{\mathrm{C}}$, for $2 \mathrm{~N} 2222$ devices, irradiated to $50 \mathrm{krad}(\mathrm{Si})$ at high dose rate and low dose rate (10 $\mathrm{mrad}(\mathrm{Si}) / \mathrm{s}$.

exceeded pre-irradiation specification limits for the lower injection regions, $0.1,1$, and $10 \mathrm{~mA}$.

The 2N2222 also exhibited considerable bias sensitivity. Fig. 7 shows the normalized current gain for devices irradiated with biased configuration and with pins grounded. The devices irradiated under bias showed higher degradation. The biased devices also showed higher part-to-part variability, due to the parametric failures of the two samples.

\section{N2907A}

The 2N2907A is a general purpose, low power PNP transistor. We investigate devices with the JANSR quality in TO-18 metal can and UBC (ceramic lid version) package types. All devices have identical wafer and lot date code.

We present data from the TO-18 packaged devices. The high dose rate data are obtained from a previous test campaign. The low dose rate testing for the UBC packaged devices are still in progress.

Fig. 8 shows the normalized current gain as a function of total dose for the 2N2907, irradiated at high dose rate and at

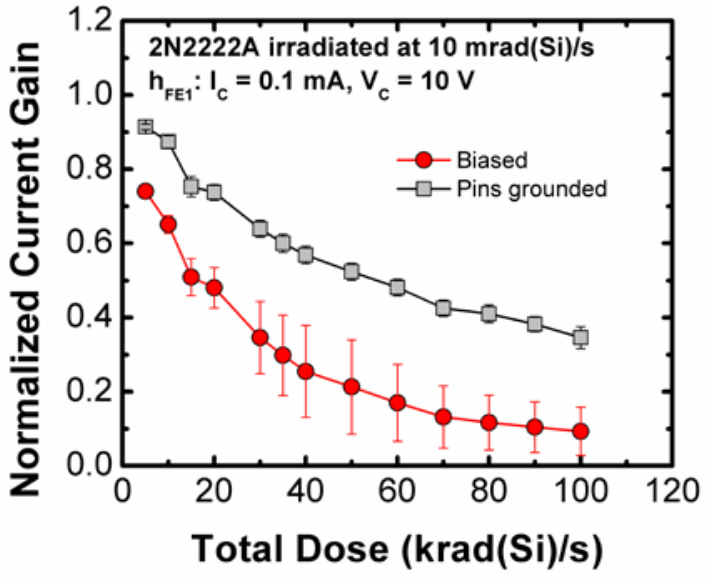

Fig. 7. Normalized current gain as a function of dose for the 2N2222, irradiated at $10 \mathrm{mrad}(\mathrm{Si}) / \mathrm{s}$, under biased and pins grounded configurations.

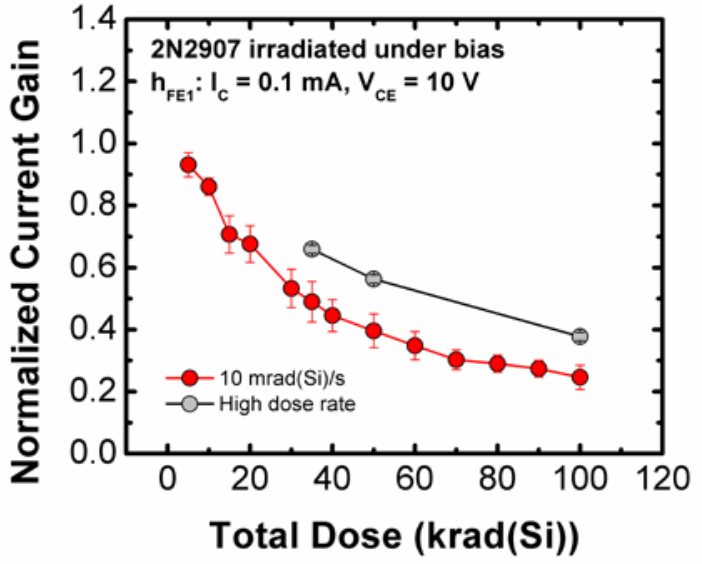

Fig. 8. Normalized current gain as a function of dose for the 2N2907, irradiated under bias at a high dose rate and $10 \mathrm{mrad}(\mathrm{Si}) / \mathrm{s}$.

$10 \mathrm{mrad}(\mathrm{Si}) / \mathrm{s}$. The LDR EF is approximately $\times 1.78$ after 100 krad(Si), as shown in Fig. 3. Fig. 9 shows the current gain as a function of the operating $\mathrm{I}_{\mathrm{C}}$, for devices irradiated to 50 $\operatorname{krad}(\mathrm{Si})$. The current gain of the devices irradiated at low dose rate exceeded the pre-irradiation specifications for the lower injection regions, 0.1 , and $1 \mathrm{~mA}$.

Fig. 10 shows the normalized current gain for devices irradiated with biased configuration and with pins grounded. We observed minimal bias sensitivity to the low dose rate response, unlike in the 2N2222 devices. The difference in the mean values between the biased and unbiased case is within the standard deviation from part-to-part variability.

\section{N5154 and 2N5153}

The 2N5154 and 2N5153 are high power switching NPN and PNP transistors, with identical electrical performance specifications. We investigate devices with JAN quality level in TO-39 metal can package type.

Fig. 11 and 12 show the normalized current gain as a function of total dose, for devices irradiated at high dose rate 


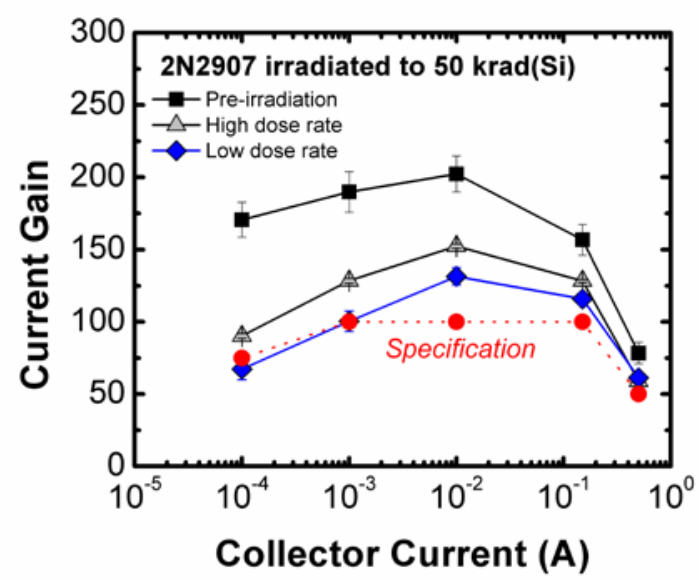

Fig. 9. Normalized current gain as a function of dose for the 2N2222, irradiated under bias at a high dose rate and low dose rate (10 $\operatorname{mrad}(\mathrm{Si}) / \mathrm{s})$.

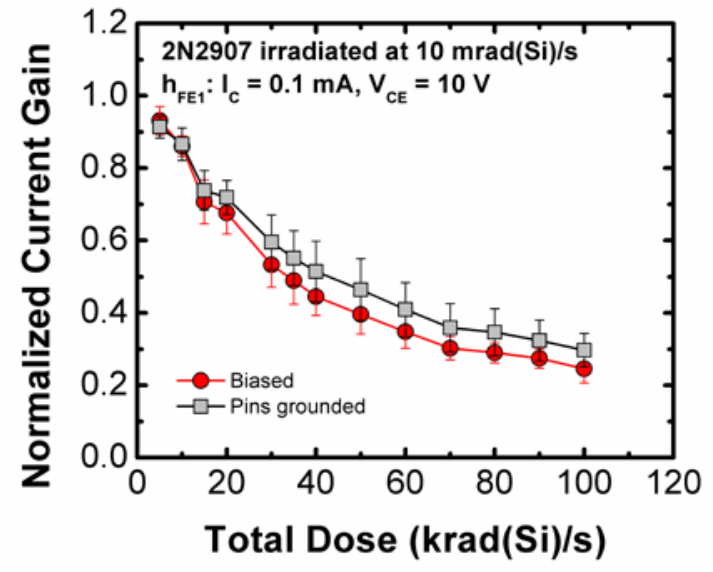

Fig. 10. Normalized current gain as a function of dose for the 2N2222, irradiated under bias at a high dose rate and $10 \mathrm{mrad}(\mathrm{Si}) / \mathrm{s}$.

and at $10 \mathrm{mrad}(\mathrm{Si}) / \mathrm{s}$, for the $2 \mathrm{~N} 5154$ and $2 \mathrm{~N} 5153$, respectively. These devices were designed to operate at high power switching applications. There was no specification for the current gain at low injection regions. The current gain degradation for $\mathrm{h}_{\mathrm{FE} 3}$ with $\mathrm{I}_{\mathrm{C}}=5 \mathrm{~A}$ and $\mathrm{V}_{\mathrm{CE}}=5 \mathrm{~V}$ was the worst case, as illustrated in Fig. 1.

The devices irradiated at low dose rate showed enhanced degradation relative to the devices irradiated at high dose rate, for both device types. However the 2N5154 showed considerably higher part-to-part variability. Nevertheless the magnitude of the degradation is low. The electrical parameters are within specification after $100 \mathrm{krad}(\mathrm{Si})$.

Fig. 11 and 12 also illustrate the irradiation bias dependence. There is minimal bias sensitivity in the radiation response. The differences in the mean degradation of the biased and unbiased 2N5154 devices are within the part-topart standard deviation of the low dose rate irradiation results.

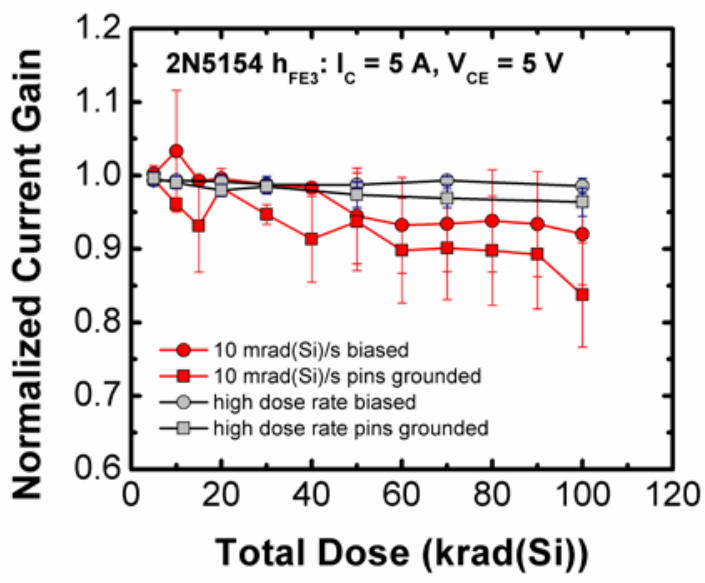

Fig. 11. Normalized current gain as a function of dose for the 2N5154, irradiated with bias and pins grounded at a high dose rate and $10 \operatorname{mrad}(\mathrm{Si}) / \mathrm{s}$.

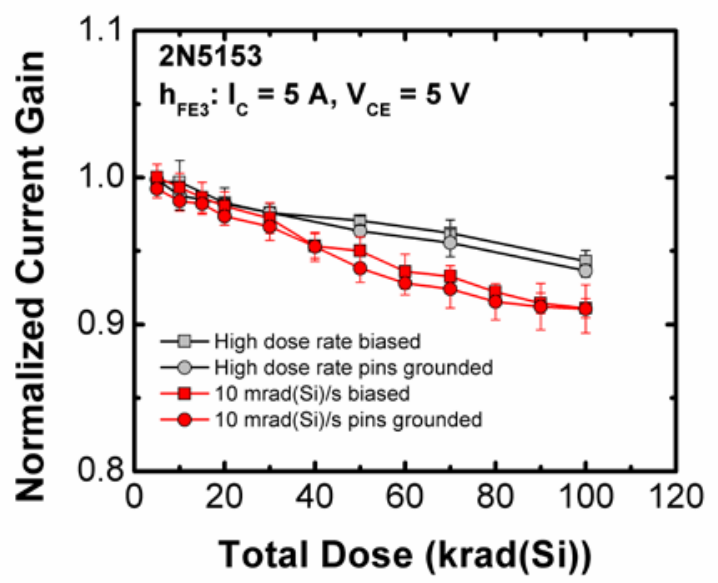

Fig. 12. Normalized current gain as a function of dose for the 2N5153, irradiated with bias and pins grounded at a high dose rate and $10 \mathrm{mrad}(\mathrm{Si}) / \mathrm{s}$

\section{N3700}

The 2N3700 is a general purpose, low power NPN transistor. We investigate devices with JANSR quality level in TO-18 metal can package type.

Fig. 13 shows the normalized current gain as a function of total dose for devices irradiated at high dose rate and at 10 $\operatorname{mrad}(\mathrm{Si}) / \mathrm{s}$, under biased configuration. The degradation at low dose rate is actually less than that at high dose rate. The high dose rate data are obtained from an earlier test campaign with the same wafer and lot date code as the devices in this study. The differences in test equipment and measurement techniques from the test campaigns may have caused disparity in the readings. Nevertheless the results showed that the 2N3700 is relatively insensitive to ELDRS at $10 \mathrm{mrad}(\mathrm{Si}) / \mathrm{s}$.

\section{N2369A}

The 2N2369A is a high speed, low power, switching NPN transistor. We investigate devices with JAN quality level in TO-18 metal can package type. 


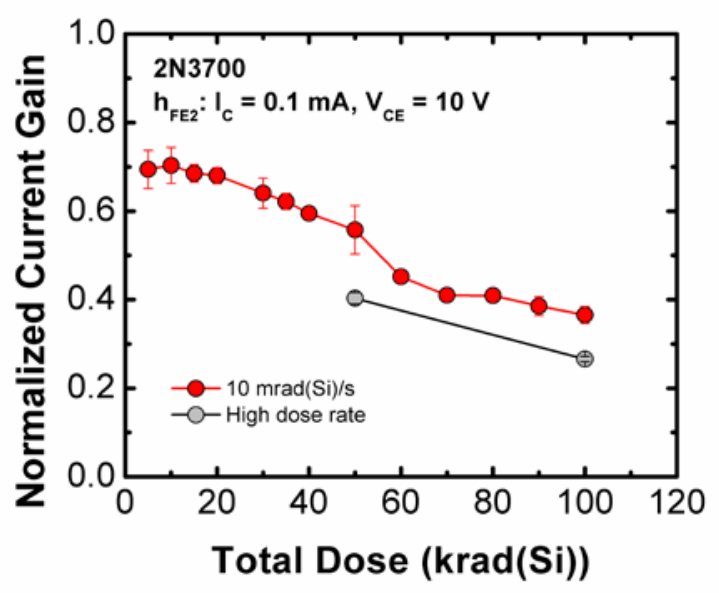

Fig. 13. Normalized current gain as a function of dose for the 2N3700, irradiated with bias at a high dose rate and $10 \mathrm{mrad}(\mathrm{Si}) / \mathrm{s}$.

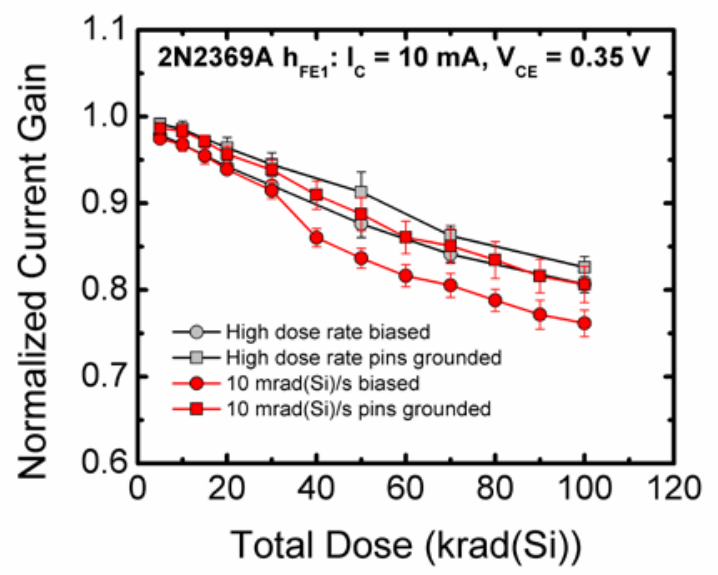

Fig. 14. Normalized current gain as a function of dose for the 2N2369A, irradiated with bias and pins grounded at a high dose rate and $10 \mathrm{mrad}(\mathrm{Si}) / \mathrm{s}$.

Fig. 14 shows the normalized current gain as a function of total dose for devices irradiated at high dose rate and at 10 $\operatorname{mrad}(\mathrm{Si}) / \mathrm{s}$. The LDR EF is less than $\times 1.5$ through 100 krad(Si), as shown in Fig. 3. The Fig. also shows that the devices biased during irradiation showed slightly enhanced degradation relative to the unbiased devices. We note that one device irradiated at $10 \mathrm{mrad}(\mathrm{Si}) / \mathrm{s}$ functionally failed after 20 $\operatorname{krad}(\mathrm{Si})$. However we do not believe the failure is caused by dose accumulation, but possibly due to electrostatic discharge. With the exception of that device, the electrical parameters are within specification up to $100 \mathrm{krad}(\mathrm{Si})$.

\section{N2857}

The 2N2857A is a low power, ultra-high frequency NPN transistor. We investigate devices with JANR quality level and TO-72 package type.

Fig. 15 shows the normalized current gain as a function of total dose for devices irradiated at high dose rate and at 10 $\operatorname{mrad}(\mathrm{Si}) / \mathrm{s}$. The electrical parameters are within specifications up to $100 \mathrm{krad}(\mathrm{Si})$, for the device irradiated at high dose rate.

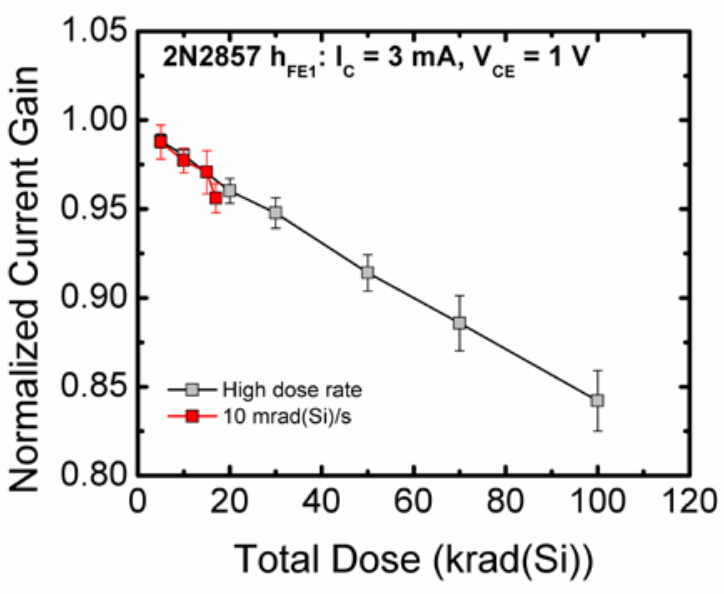

Fig. 15. Normalized current gain as a function of dose for the 2N2857, irradiated with bias and pins grounded at a high dose rate and $10 \mathrm{mrad}(\mathrm{Si}) / \mathrm{s}$.

The low dose rate irradiation is still in progress. We do not see significant low dose rate enhancement up to $\sim 20$ $\operatorname{krad}(\mathrm{Si})$. We also plan to investigate the bias dependence in the future.

\section{Conclusion}

We have presented results of low dose rate total dose irradiation on several families of discrete bipolar transistors. We observed enhanced low dose rate sensitivity in the current gain degradation for several device types. In particular, the 2N2222 devices irradiated under bias at $10 \mathrm{mrad}(\mathrm{Si}) / \mathrm{s}$ showed parametric failures after $40 \mathrm{krad}(\mathrm{Si})$. The unbiased devices showed much less degradation. We found a LDR EF of $\times 3.91$ after $100 \mathrm{krad}(\mathrm{Si})$ for the devices irradiated under bias. Although the 2N2907 exhibited smaller magnitude of ELDRS, the devices irradiated at $10 \mathrm{mrad}(\mathrm{Si}) / \mathrm{s}$ showed parametric failure after $50 \mathrm{krad}(\mathrm{Si})$. The LDR EF is $\times 1.78$ after $100 \mathrm{krad}(\mathrm{Si})$. The $2 \mathrm{~N} 2907$ also showed minimum bias sensitivity in the radiation response. Several other device types showed various magnitudes of ELDRS, such as the 2N5153, 2N5154 and 2N2369A. However the degradation levels are relatively small, such that parameters are within specification up to $100 \mathrm{krad}(\mathrm{Si})$. We also observed that the magnitude of the radiation-induced degradation generally varied inversely with the minimum device operating range. However the level of ELDRS did not show similar correlation. Further investigation is required to better understand why devices of similar process technology show vastly different low dose rate response.

The results also showed various levels of bias sensitivity in the low dose rate response. The unbiased case is important for space application, as many systems utilize cold spare devices. Furthermore, the bias configuration applied in this study may not represent the worst case for the low dose rate response for all device types. Therefore, the appropriate evaluation test method is to test with the application bias condition. 
The space radiation community has generally neglected the radiation tolerance of discrete BJTs. These devices are commonly used in satellite systems without sufficient test data. Even when total dose data are available, there is rarely a case where both high and low dose rate $(\leq 10 \mathrm{mrad}(\mathrm{Si}) / \mathrm{s})$ data exist for ELDRS analysis. The results presented here show that we need to consider the low dose rate total dose response of discrete BJTs for space applications. The appropriate test dose rate is one that simulates the dose rate during the mission, which can reach 1 to 2 orders of magnitude below the current standard test dose rate of $10 \mathrm{mrad}(\mathrm{Si}) / \mathrm{s}$. We plan to further investigate the ultra-low dose rate response (dose rates less than $10 \mathrm{mrad}(\mathrm{Si}) / \mathrm{s})$ in our next phase of the study.

\section{Acknowledgment}

The authors would like to thank Tom Ward and Yevgeniy Geraschenko for organizing the radiation schedule. The authors would also like to thank Geraldine Chaumont for sharing test results and insightful discussions.

\section{References}

[1] A. H. Johnston, G. M. Swift, and B. G. Rax, "Total dose effects in conventional bipolar transistors and linear integrated circuits,” IEEE Trans. Nucl. Sci., vol. 41, no. 6, pp. 2427-2436, Dec. 1994.

[2] MIL-STD-883-H, Test Method 1019.8, Ionizing Radiation (Total Dose) Test Procedure Feb. 26, 2010.
[3] R. N. Nowlin, R. D. Schrimpf, E. W. Enlow, W. E. Combs, R. L. Pease, "Mechanisms of Ionizing Radiation Induced Degradation in Modem Bipolar Devices," Proceedings of the Bipolar Circuits and Technology Meeting, Issue 9-10, pp. $174-177$, Sept. 1991.

[4] D. M. Fleetwood, S. L. Kosier, R. N. Nowlin, R. D. Schrimpf, R. A. Reber, Jr., M. DeLaus, P. S. Winokur, A. Wei, W. E. Combs, and R. L. Pease, "Physical mechanisms contributing to enhanced bipolar gain degradation at low dose rates,” IEEE Trans. Nucl. Sci., vol. 41, no. 6, pp. 18711883, Dec. 1994.

[5] D. M. Fleetwood, R. D. Schrimpf, S. T. Pantelides, R. L. Pease, and G. W. Dunham, "Electron capture, hydrogen release and ELDRS in bipolar linear devices," IEEE Trans. Nucl. Sci., vol. 55, no. 6, part 1, pp. 2986-2991, Dec. 2008.

[6] R. L. Pease et al., "The Effects of Hydrogen on the Enhanced Low Dose Rate Sensitivity (ELDRS) of Bipolar Linear Circuits,” IEEE Trans. Nucl. Sci., vol. 55, pp. 3169-3173, Dec. 2008.

[7] D. Chen, R. L. Pease, K. Kruckmeyer, J. Forney, A. Phan, M. Carts, S. Cox, S. Burns, R. Albarian, B. Holcombe, B. Little, J. Salzman, G. Chaumont, H. Duperray, A. Ouellet, S. Buchner, and K. LaBel, "Enhanced low dose rate sensitivity at ultra-low dose rates,” IEEE Trans. Nucl. Sci., vol. 58, no. 6, part 1, pp. 2983 - 2990, Dec. 2008.

[8] G. Chaumont "Dose rate effect on bipolar transistors," presented at the JEDEC meeting, Tempe, AZ, Feb $15^{\text {th }} 2011$.

[9] E. W. Enlow, R. L. Pease, W. E. Combs, and D. G. Platteter, "Total dose induced hole trapping in trench oxides," IEEE Trans. Nucl. Sci., vol. 36, pp. 2415-2422, 1989. 